\title{
Transcriptomic insights on the $A B C$ transporter gene family in the salmon louse Caligus rogercresseyi
}

\author{
Valentina Valenzuela-Muñoz ${ }^{1}$, Armin Sturm² and Cristian Gallardo-Escárate ${ }^{1^{*}}$
}

\begin{abstract}
Background: ATP-binding cassette $(A B C)$ protein family encode for membrane proteins involved in the transport of various biomolecules through the cellular membrane. These proteins have been identified in all taxa and present important physiological functions, including the process of insecticide detoxification in arthropods. For that reason the ectoparasite Caligus rogercresseyi represents a model species for understanding the molecular underpinnings involved in insecticide drug resistance.

Methods: Ilumina sequencing was performed using sea lice exposed to 2 and 3 ppb of deltamethrin and azamethiphos. Contigs obtained from de novo assembly were annotated by Blastx. RNA-Seq analysis was performed and validated by qPCR analysis.

Results: From the transcriptome database of $C$. rogercresseyi, 57 putative members of $A B C$ protein sequences were identified and phylogenetically classified into the eight subfamilies described for $A B C$ transporters in arthropods. Transcriptomic profiles for ABC proteins subfamilies were evaluated throughout $C$. rogercresseyi development. Moreover, RNA-Seq analysis was performed for adult male and female salmon lice exposed to the delousing drugs azamethiphos and deltamethrin. High transcript levels of the $A B C B$ and $A B C C$ subfamilies were evidenced. Furthermore, SNPs mining was carried out for the $A B C$ proteins sequences, revealing pivotal genomic information.

Conclusions: The present study gives a comprehensive transcriptome analysis of ABC proteins from C. rogercresseyi, providing relevant information about transporter roles during ontogeny and in relation to delousing drug responses in salmon lice. This genomic information represents a valuable tool for pest management in the Chilean salmon aquaculture industry.
\end{abstract}

Keywords: Caligus rogercresseyi, ABC transporters, RNA-Seq, Deltamethrin, Azamethiphos, SNPs

\section{Background}

Caligus rogercresseyi, a sea louse, is a widely prevalent parasite in the Chilean aquaculture industry $[1,2]$. This ectoparasite belongs to the Caligidae family, which includes species such as Lernaeocera branchialis, Caligus clemensi, and Lepeophtheirus salmonis, with this final species having greater prevalence in countries such as Scotland, Norway, Canada, and England [3]. Although not associated with host mortality, an infection of C. rogercresseyi is a highly stressful condition for fish,

\footnotetext{
* Correspondence: crisgallardo@udec.cl

'Laboratory of Biotechnology and Aquatic Genomics, Interdisciplinary Center for Aquaculture Research (INCAR), University of Concepción, PO. Box 160-C, Concepción, Chile

Full list of author information is available at the end of the article
}

which is reflected by lower culture performance and a depression of the host's immune system, which thus increases susceptibility to other types of contagious diseases [1-4].

Numerous delousing drugs have been used worldwide for the control of this ectoparasite [5]. However, many studies suggest that the effectiveness of different treatments for sea lice principally depends on the developmental stage of the parasite and the delousing drugs used, for example, there are reports that have mentioned the effect of emamectin benzoate in chitin synthesis which results in a fragile exoskeleton after moulting [5-9]. One of the protein families which has shown detoxifying effects against drugs are the $\mathrm{ABC}$ transporters. 
These types of transporters have been widely related to the generation of resistance to emamectin benzoate in L. salmonis $[10,11]$.

The ATP-binding cassette $(A B C)$ proteins family is ubiquitous in the animal kingdom, and has even been found in plants. Most of these $\mathrm{ABC}$ proteins are integral membrane proteins that use ATP to transport biomolecules through the plasma membrane [12]. In eukaryotes, this family has a characteristic organization marked by two transmembrane domains (TMD) that are formed by five or six helixes which determine the specificity of the transporter $[13,14]$. Moreover, this family also presents two cytosolic nucleotide binding domains (NBD), and these bind and hydrolyze the ATP necessary for transporting substances across the membrane [13,14]. The NBD is a highly conserved sequence that presents characteristic sites such as Q-look, the $\mathrm{H}$-motif, and the LSGGQ-motif $[14,15]$. It is possible to divide ABC transporters into the following two groups: those present only in prokaryotes and which require substrate-binding proteins for transport, and those found only in eukaryotes and that bind directly to the substrate from the interior of the cell [15]. The substances transported by ABC transporters include amino acids, sugars, lipids, inorganic ions, polysaccharides, metals, peptides, and toxic substances [16].

The ABC proteins family is comprised of subfamilies that are differentiated according to domain and sequence structures [16]. In mammals, seven subfamilies (A-G) have been identified, whereas in arthropods and zebra fish, eight subfamilies $(\mathrm{A}-\mathrm{H})$ have been found $[12,16]$. While in prokaryotic organisms such as Escherichia coli, the ABC family has been subdivided into 22 subfamilies with transporter activity and 24 with exporter activity [17]. Of the eight subfamilies describe in arthropod, the $\mathrm{E}$ and $\mathrm{F}$ subfamilies are the only ones without transporter functions. The $\mathrm{ABC}$ transporter $\mathrm{E}$ subfamily (ABCE) members act as inhibitors of RNase L and participate in assembling the preinitiation complex, while the ABCF subfamily plays a role in assembling ribosomes and in protein translation [12]. Currently, the $\mathrm{ABC}$ transporter subfamilies have only been characterized in eight arthropod species, which are D. melanogaster [13], Anopheles gambiae [18], Apis mellifera [19], Bombix mori [20], Tribolium casteneum [21], Tetranychus urticae [22], Daphia pulex [12], and, recently, Tigriopus japonicus [23].

The ABCB subfamily is especially of interest given its ability to transport drugs [24,25], with P-glycoprotein (P-gp) being the first transporter identified within this family [26]. Furthermore, the ABCC and ABCG families have been reported to have a similar detoxifying function $[16,27]$. Given their roles related to the detoxification of drugs, these proteins have been termed multidrug resistance proteins (MRPs). In invertebrates, MRPs have been associated with the generation of resistance to insecticides, including in species such as Caenorhabditis elegans, Tricho plusiani [28], and Aedes aegypti [29], among others. In the ectoparasites Lepeophtheirus salmonis [10] and Caligus rogercresseyi [30], a close association has been found between the generation of resistance to emamectin benzoate $(\mathrm{EMB})$ and the transcriptomic response of P-gp. Likewise, an exhaustive study on the different ABC transporter families in $D$. pulex was carried out with the purpose of understanding the adaptation mechanisms that this crustacean uses in response to toxic compounds [12], and a recent study in $L$. salmonis characterized an additional four MRPs [31]. However, these MRPs in L. salmonis did not present differences in transcript expression between EMB resistant/susceptible strains.

C. rogercresseyi is an ectoparasite responsible for significant economic losses in the Chilean salmon aquaculture industry, and, as with L. salmonis, this species has demonstrated resistance to the drugs currently used in infestation control [32-34]. Given the role that ABC transporters play in pharmaceutical resistance in invertebrates, the objective of the present study was to identify members of the distinct $\mathrm{ABC}$ subfamilies and determine expression patterns during the distinct stages of development in C. rogercresseyi. Moreover, RNA-Seq analysis was performed in adult salmon lice exposed to the delousing drugs deltamethrin and azamethiphos in order to determine the modulation of distinct $\mathrm{ABC}$ proteins in response to drugs currently used in the control of $C$. rogercresseyi.

\section{Methods}

\section{Samples and bioassays}

Adult male and female sea lice were collected from a commercial farm located in Region de los Lagos of Chile (41 $\left.40^{\prime} 48.5^{\prime \prime} \mathrm{S} ; 73^{\circ} 02^{\prime} 31.34^{\prime \prime} \mathrm{O}{ }^{\prime \prime}\right)$. Permissions for sea lice collection were authorized by Marine Harvest S.A, Ruta 226, Km. 8, Camino El Tepual, Puerto Montt, Chile.

For the bioassays, deltamethrin $\left(\right.$ AlphaMax $\left.^{\oplus}\right)$ was prepared via serial dilutions with seawater to four concentrations $(0,1,2,3 \mathrm{ppb})$. A stock solution of $10 \mathrm{ppm}$ was also prepared for each bioassay by diluting $1 \mathrm{ml}$ of deltamethrin in $999 \mathrm{ml}$ of seawater. In regards to azamethiphos (Bayer ${ }^{\circledR}$ ), a stock solution of $1 \mathrm{ppm}$ diluted in methanol and three serial dilutions with seawater to four concentrations $(0,1,3,10 \mathrm{ppb})$ were prepared. Ten sea lice adults (five females and five males) were exposed to each concentration of deltamethrin and azamethiphos using petri plates containing $50 \mathrm{ml}$ of seawater (total individuals =30). Each experiment was carried out in triplicate. The exposure period to either deltamethrin or azamethiphos was 40 and $30 \mathrm{~min}$, respectively. During exposure, salmon lice were maintained at $12^{\circ} \mathrm{C}$. After $24 \mathrm{~h}$, the organisms were fixed in theRNAlater ${ }^{\odot}$ RNA Stabilization Reagent 
(Ambion, USA) and stored at $-80^{\circ} \mathrm{C}$ for subsequent RNA extraction. The protocols for bioassays were performed according to the SEACH Consortium (2006). All laboratory infections and culture procedures were carried out under guidelines approved by the ethics committee of the University of Concepción and under appropriate veterinary supervision.

\section{High-throughput sequencing}

The concentration $2 \mathrm{ppb}$ and $3 \mathrm{ppb}$ of deltamethrin or azamethiphos, respectively, was determined as EC50 in the bioassay. For this reason 15 females and 15 males of each group exposed to these concentrations, were used for MiSeq cDNA libraries preparation. Total RNA was extracted from pooled individuals for each sex $(\mathrm{N}=10)$ using the RiboPure ${ }^{\mathrm{Tm}}$ Kit (Ambion $^{\circ}$, Life Technologies ${ }^{\mathrm{Tm}}$, USA) following the manufacturer's instructions. Quantity, purity, and quality of isolated RNA were measured in the TapeStation 2200 (Agilent Technologies Inc., Santa Clara, CA, USA) using the R6K Reagent Kit according to the manufacturer's instructions; samples with RIN over 8.0 were used for library preparation. Subsequently, doublestranded cDNA libraries were constructed using the TruSeq RNA Sample Preparation Kit v2 (Illumina ${ }^{\circ}$, San Diego, CA, USA). Two biological replicates for each sample pool were sequenced by the MiSeq (Illumina ${ }^{\circ}$ ) platform using sequenced runs of 2x251 paired-end reads at the Laboratory of Biotechnology and Aquatic Genomics, Interdisciplinary Center for Aquaculture Research (INCAR), University of Concepción, Chile. The cleaned short read sequences were deposited in the Sequence Read Archive (SRA) (http:// www.ncbi.nlm.nih.gov/sra) under the accession number SRX864101 and SRX864102 for deltamethrin and azamethiphos, respectively.

\section{Sequence annotation and RNA-Seq analysis}

From the EST-database generated for $C$. rogercresseyi [35], contigs were annotated using a database constructed from $\mathrm{ABC}$ transporter sequences described for D. pulex [12] and enriched with EST data for arthropods in order to determine putative gene descriptions. A cutoff E-value of $1 \mathrm{E}-05$ was used.

The same EST database generated for C. rogercresseyi was used as a reference for RNA-Seq analysis. Using the CLC Genomic Workbench software, the reads obtained from female and male adult controls and individuals exposed to azamethiphos or deltamethrin were separately mapped against $\mathrm{ABC}$ transporter contigs. The RNA-Seq settings were a minimum length fraction $=0.6$ and a minimum similarity fraction (long reads) $=0.5$. The expression value was set as a reads per kilobase of exon model (RPKM). This normalized the number of reads to the size of assembled contigs and allowed for assessing the transcripts that were overexpressed among different groups. Furthermore, to compare differentiated transcript responses between sexes, the reads obtained for females and males were mapped separately over the $A B C$ contigs using the RNA-Seq settings previously described [35]. A similar analysis was carried out between control and exposure groups using the new contigs obtained from de novo assembly as a reference. The metric distance was calculated using the Manhattan method, where the mean expression level in 5-6 rounds of k-means clustering was subtracted. Finally, a Kal's statistical analysis test [36] was used to compare gene expression levels for larval stages and adults in terms of the $\log 2$ fold change $(\mathrm{P}=0.0005$; FDR corrected).

\section{Amino acid sequence analyses}

Protein alignments were conducted using MUSCLE, and phylogenetic trees were constructed using the neighborjoining method with 1,000 bootstrap repetitions. Both analyses were carried out in Geneious 6.0.5 [37].

\section{qPCR validation}

Contig sequences of $A B C$ subfamilies were obtained from the Illumina MiSeq database for $C$. rogercresseyi and used as a template for primer design with the Primer3 Tool [38] included in the Geneious Pro software [37] (Additional file 1: Table S1). For gene amplification, total RNA was isolated from sea louse exposed to $3 \mathrm{ppb}$ of azamethiphos and $2 \mathrm{ppb}$ of deltamethrin, using the TRI Reagent (Invitrogen, Carlsbad, CA, USA) protocol. The purity was determined (ratio A260/A280) with a Nanodrop ND1000 spectrophotometer (Thermo Fisher Scientific, Copenhagen, USA), and the integrity was determined by agarose gel under denaturant conditions. From $200 \mathrm{ng} / \mu \mathrm{l}$ of total RNA, cDNA was synthetized using the RevertAid $\mathrm{H}$ Minus First Strand cDNA Synthesis Kit (Thermo Scientific, Glen Burnie, Maryland, USA). The qPCR runs were performed with StepOnePlus ${ }^{\text {tw }}$ (Applied Biosystems, Life Technologies, USA) using the comparative $\Delta \mathrm{Ct}$ method. $\beta$-tubulin was selected as the housekeeping gene (HKG) [39]. Each reaction was conducted with a volume of $10 \mu \mathrm{L}$ using the Maxima ${ }^{\circ}$ SYBR Green/ROX qPCR Master Mix (Thermo Scientific, USA). The amplification conditions were as follows: $95^{\circ} \mathrm{C}$ for $10 \mathrm{~min}, 40$ cycles at $95^{\circ} \mathrm{C}$ for $30 \mathrm{~s}, 60^{\circ} \mathrm{C}$ for $30 \mathrm{~s}$, and $72^{\circ} \mathrm{C}$ for $30 \mathrm{~s}$. The data obtained were analyzed through the Kruskal-Wallis test with the Statistica software (Version 7.0, StatSoft, Inc.). Statistically significant differences were accepted with a $\mathrm{p}<0.05$.

\section{SNPs mining and validation}

Using the assembly obtained for all identified $A B C$ transporters, SNPs mining was performed using the Genomics Workbench 5.0.1 software (CLC bio, Denmark). The parameters used were as follows: window length $=11$, maximum gap and mismatch count $=2$, minimum average 
quality of surrounding bases $=15$, minimum quality of central base $=20$, maximum coverage $=100$, minimum coverage $=8$, minimum variant frequency $(\%)=35.0$, and maximum expected variations (ploidy) $=2$.

\section{Results}

Identification of $A B C$ transporter subfamily genes from C. rogercresseyi

Through BLASTx analysis, 57 full or partial sequences were identified $A B C$ transporter from transcriptome database described by Gallardo-Escárate et al. [35] and by using arthropod $\mathrm{ABC}$ transporter sequences described in public databases as a reference (Additional file 1: Table S2). Phylogenetic analysis revealed a relationship between seven $C$. rogercresseyi contigs and the ABCA subfamily described in D. pulex (Figure 1). From the seven contigs annotated for the ABCA subfamily, one of these presented an encoding sequence of 2,208 amino acids and the structure typical of this subfamily, with a large extracellular loop between the first two

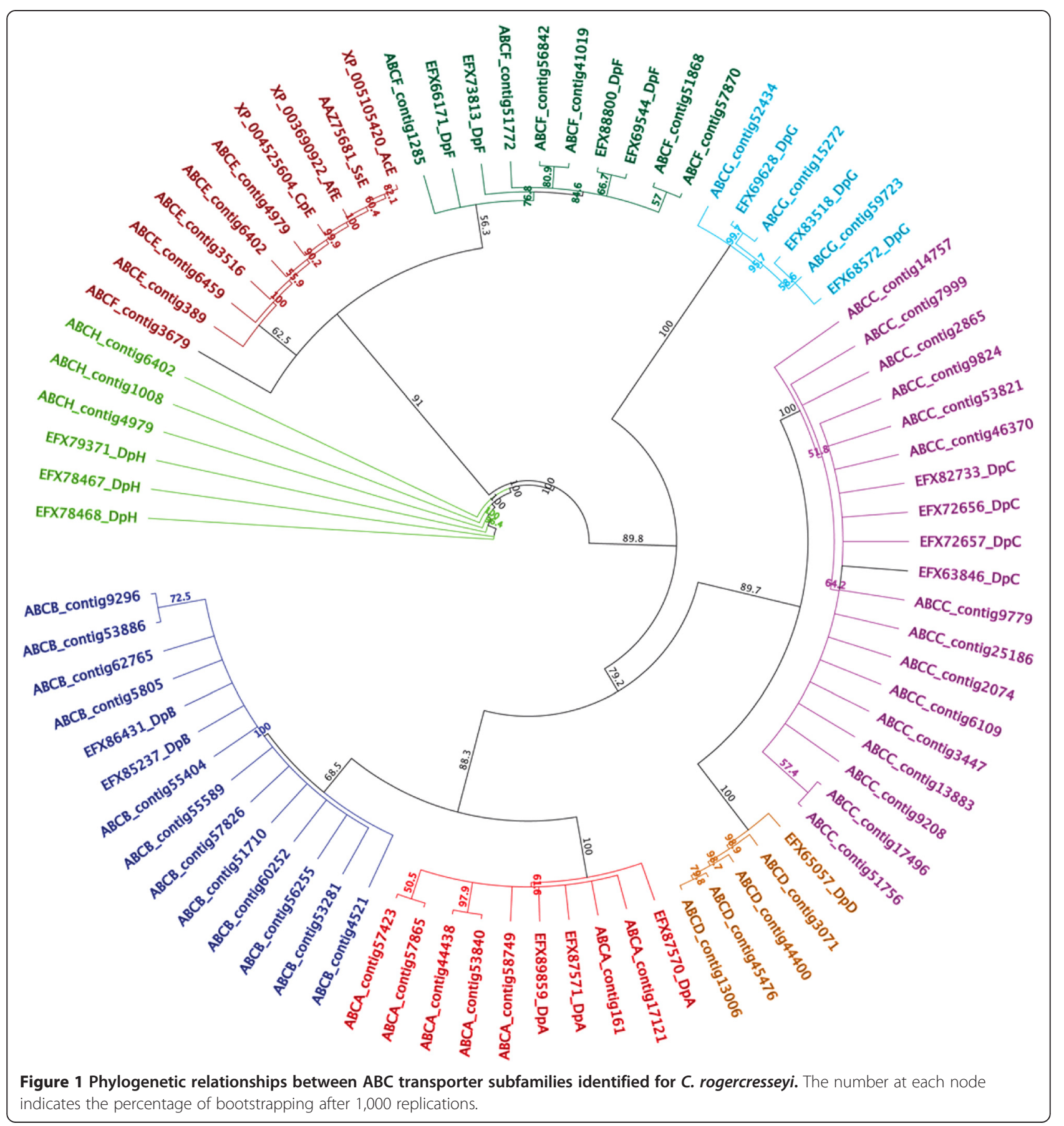


helices of the TMD (Table 1). BLASTp analysis demonstrated an identity of $39.8 \%$ and $39.3 \%$ with sequences described for Lottia gigantea (ESP01294) and Danio rerio (XP_005173137), respectively. Moreover, twelve contigs were annotated for the ABCB subfamily. Phylogenetic analysis grouped these sequences with the ABCA subfamily described for $D$. pulex (Figure 1). Contig 4,521 appeared as a full transporter encoding for 2,064 amino acids (Table 1). This also presented a 100\% identity to the P-gp previously described in L. salmonis (ADT63773) and C. rogercresseyi (AHC54388). Thirteen contigs presented homology with the $\mathrm{ABCC}$ subfamily (Figure 1), with nine presenting high homology to $\mathrm{ABCC} 1$ transporters and four presenting homology with the ABCC4 subfamily (Additional file 1: Table S1). Also, two contigs presented high homology with sulfonylurea receptor (SUR) gene, member of ABCC subfamily (Additional file 1: Table S2). For the ABCD subfamily, four contigs were identified. Phylogenetic analysis grouped these sequences with orthologs described in D. pulex (Figure 1). BLASTp analysis demonstrated a $38.1 \%$ and $38.2 \%$ identity to ABCD4 described in Homo sapiens (NP_005041) and Mus musculus (NP_033018), respectively. From phylogenetic analysis, a relationship was observed between the $\mathrm{ABCE}$ and $\mathrm{ABCF}$ subfamilies of $C$. rogercresseyi (Figure 1). The sequences that were annotated to the $\mathrm{ABCE}$ subfamily presented an identity of $80.8 \%$ and $81.1 \%$ with homologs described in A. florea (XP_003690992) and Pediculus humanus (XP_002424051), respectively. The sequenced members of the ABCF subfamily presented an identity of $55.3 \%$ and $55.1 \%$ to sequences reported in $A$. aegypti (XP_001654470) and D. pulex (EFX69544), respectively. Furthermore, three contigs presented high homology with the ABCG subfamily (Additional file 1: Table S2) and were grouped with members of the ABCG subfamily described for D. pulex (Figure 1). Among these, contig 15272 encoded for haft transporters with the NBD-TMD domain traits (Table 1). Finally, three contigs of $C$. rogercresseyi were annotated as $\mathrm{ABCH}$ transporters (Figure 1). One of these encoded for 1,045 amino acids and presented an organization similar to that observed for ABCG transporters (Table 1).

\section{Transcriptomic profile of $A B C$ transporters during larval} stages and in adult $C$. rogercresseyi

RNA-Seq analysis was carried out in order to evaluate the transcriptome profiles of $\mathrm{ABC}$ transporters during the developmental stages of $C$. rogercresseyi (Figure 2). From the expression profiles in the larval nauplius I-II stages, the subfamilies $A B C A / B / C / D$ were highly regulated. In the infective copepodid stage, the $\mathrm{ABCC} / \mathrm{E} / \mathrm{F} / \mathrm{G} / \mathrm{H}$ transporters were upregulated. The $\mathrm{ABCD} / \mathrm{E} / \mathrm{F}$ subfamilies were highly regulated in chalimus I-II stages, while in the chalimus III-IV stages, the $\mathrm{ABCA} / \mathrm{B} / \mathrm{C} / \mathrm{F}$ subfamilies were upregulated (Figure 2). Furthermore, differences in expression profiles were observed between female and male $C$. rogercresseyi individuals. The $\mathrm{ABCD} / \mathrm{F}$ subfamilies were upregulated in females, while in males, the $\mathrm{ABCB} / \mathrm{C}$ subfamilies evidenced high regulation (Figure 2).

\section{Transcriptomic profiles of $A B C$ transporters in response to delousing drugs}

RNA samples obtained from female and male C. rogercresseyi individuals exposed to $2 \mathrm{ppb}$ of azamethiphos or $3 \mathrm{ppb}$ of deltamethrin were sequenced using the MiSeq Illumina platform (Table 2). The sequencing runs of salmon lice exposed to azamethiphos yielded a total of 9.06 million reads for males and 10.4 million reads for females, with an average length of 223 and $254 \mathrm{bp}$, respectively. From adults exposed to deltamethrin, a total of $51.08 \mathrm{M}$ and 27.54 $\mathrm{M}$ for males and females were generated, respectively, both with an average length of $219 \mathrm{bp}$.

Comparing the transcriptomic response of C. rogercresseyi adults exposed to azamethiphos, deltamethrin and the control group, the adults exposed to deltamethrin and the control group presented similar expression profiles of $A B C$ transporters (Figure 3). The $A B C B$ and $A B C C$ subfamilies were upregulated in adult sea lice

Table 1 Amino acid position of conserved domain for $A B C$ subfamily of $C$. rogercresseyi

\begin{tabular}{|c|c|c|c|c|c|c|c|}
\hline \multirow[b]{2}{*}{ Contig } & \multirow[b]{2}{*}{ Description } & \multirow[b]{2}{*}{ Type transporter } & \multirow[b]{2}{*}{$\begin{array}{l}\text { Lenght predict amino } \\
\text { acid sequence }\end{array}$} & \multicolumn{4}{|c|}{ Amino acid position } \\
\hline & & & & TMD1 & NBD1 & TMD2 & NBD2 \\
\hline Contig 161 & $A B C$ protein, subfamily $A B C A$ & Full & 2,209 & $550-754$ & $814-1,032$ & $1,583-1,739$ & $1,885-2,091$ \\
\hline Contig 4521 & $A B C$ protein, subfamily $A B C B$ & Full & 1,131 & $28-255$ & $336-678$ & $711-988$ & $1,035-1,269$ \\
\hline Contig 2865 & $A B C$ protein, subfamily $A B C C$ & Full & 1,456 & $284-565$ & $607-818$ & $890-1,168$ & $1,207-1434$ \\
\hline Contig 3071 & $A B C$ protein, subfamily $A B C D$ & Half & 538 & $7-243$ & $327-532$ & - & - \\
\hline Contig 3516 & $A B C$ protein, subfamily $A B C E$ & Half & 616 & - & $92-347$ & - & $363-608$ \\
\hline Contig 1258 & $A B C$ protein, subfamily $A B C F$ & Half & 544 & - & $6-224$ & - & $319-513$ \\
\hline Contig15272 & $A B C$ protein, subfamily $A B C G$ & Half & 975 & - & $58-238$ & $327-583$ & - \\
\hline Contig 6402 & $\mathrm{ABC}$ protein, subfamily $\mathrm{ABCH}$ & Half & 745 & - & $34-249$ & $496-710$ & - \\
\hline
\end{tabular}

TMDs: transmembrane domains. NBDs: nucleotide-binding domains. 


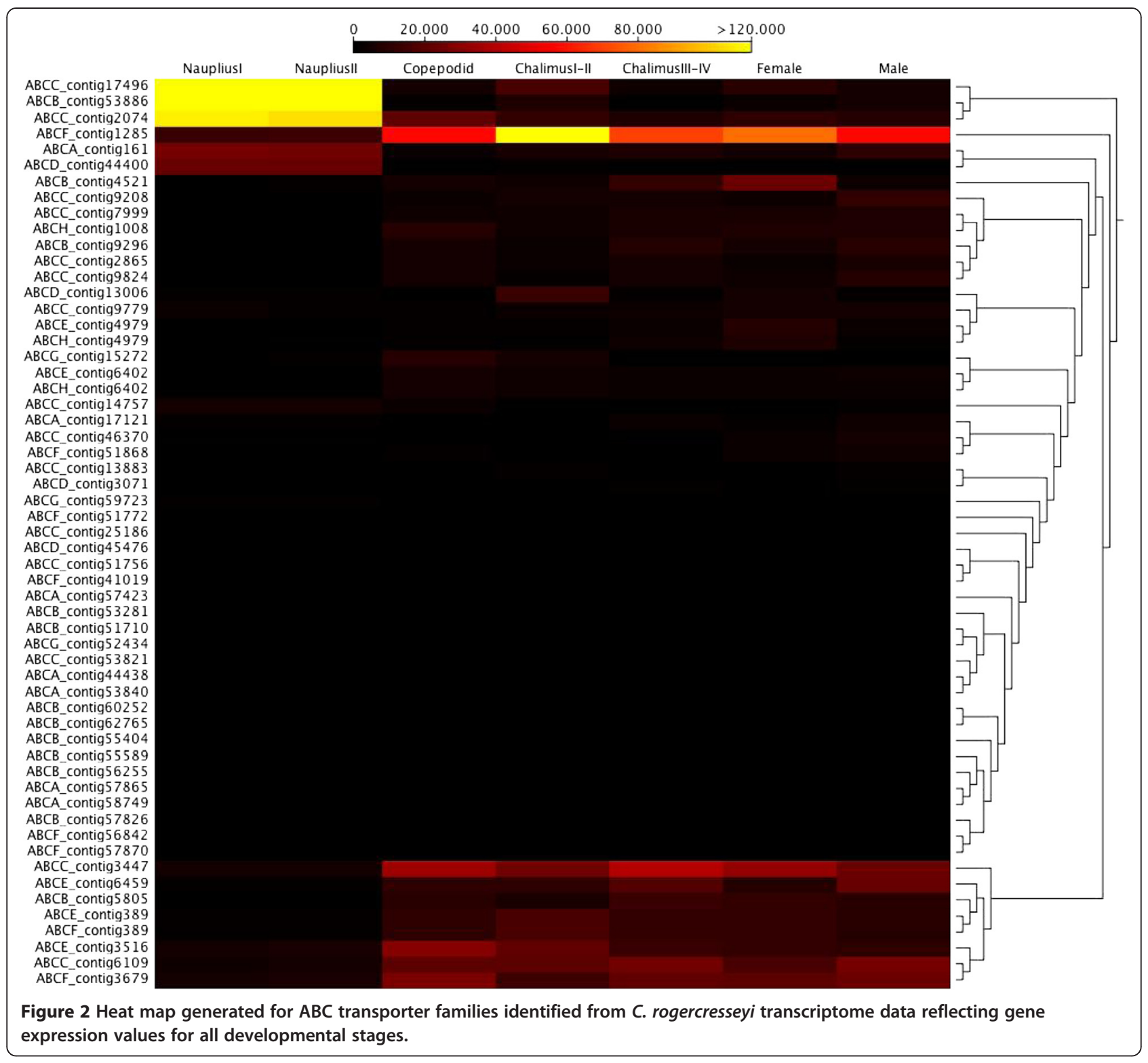

exposed to azamethiphos (Table 3). Also, increased expression was observed for both females and males in contigs annotated as members of the ABCA/D subfamilies in response to azamethiphos (Figure 4). An opposite effect was observed in contig 1285 annotated as an
ABCF transporter, which was downregulated in sea lice exposed to azamethiphos. Furthermore, different transcriptomic responses were observed between sexes in response to azamethiphos, where the $\mathrm{ABCB}$ and $\mathrm{ABCC}$ subfamilies were only up-regulated in males. In response

Table 2 Statistical summary of Caligus rogercresseyi transcriptome following exposure to Azamethiphos or Deltamethrin

\begin{tabular}{|c|c|c|c|c|c|c|}
\hline & \multicolumn{2}{|c|}{ Control } & \multicolumn{2}{|c|}{ Azamethiphos } & \multicolumn{2}{|c|}{ Deltamethrin } \\
\hline & Male & Female & Male & Female & Male & Female \\
\hline Reads (M) & 32.29 & 30.19 & 9.06 & 10.40 & 51.08 & 27.54 \\
\hline Average length (bp) & 142 & 148 & 223 & 254 & 218 & 219 \\
\hline Nucleotide number (Gb) & 4.59 & 4.47 & 2.03 & 2.64 & 11.16 & 6.05 \\
\hline Contigs & 38,177 & 32,172 & 38,045 & 40,58 & 38,536 & 30,212 \\
\hline Average length (bp) & 729 & 799 & 785 & 818 & 877 & 922 \\
\hline
\end{tabular}




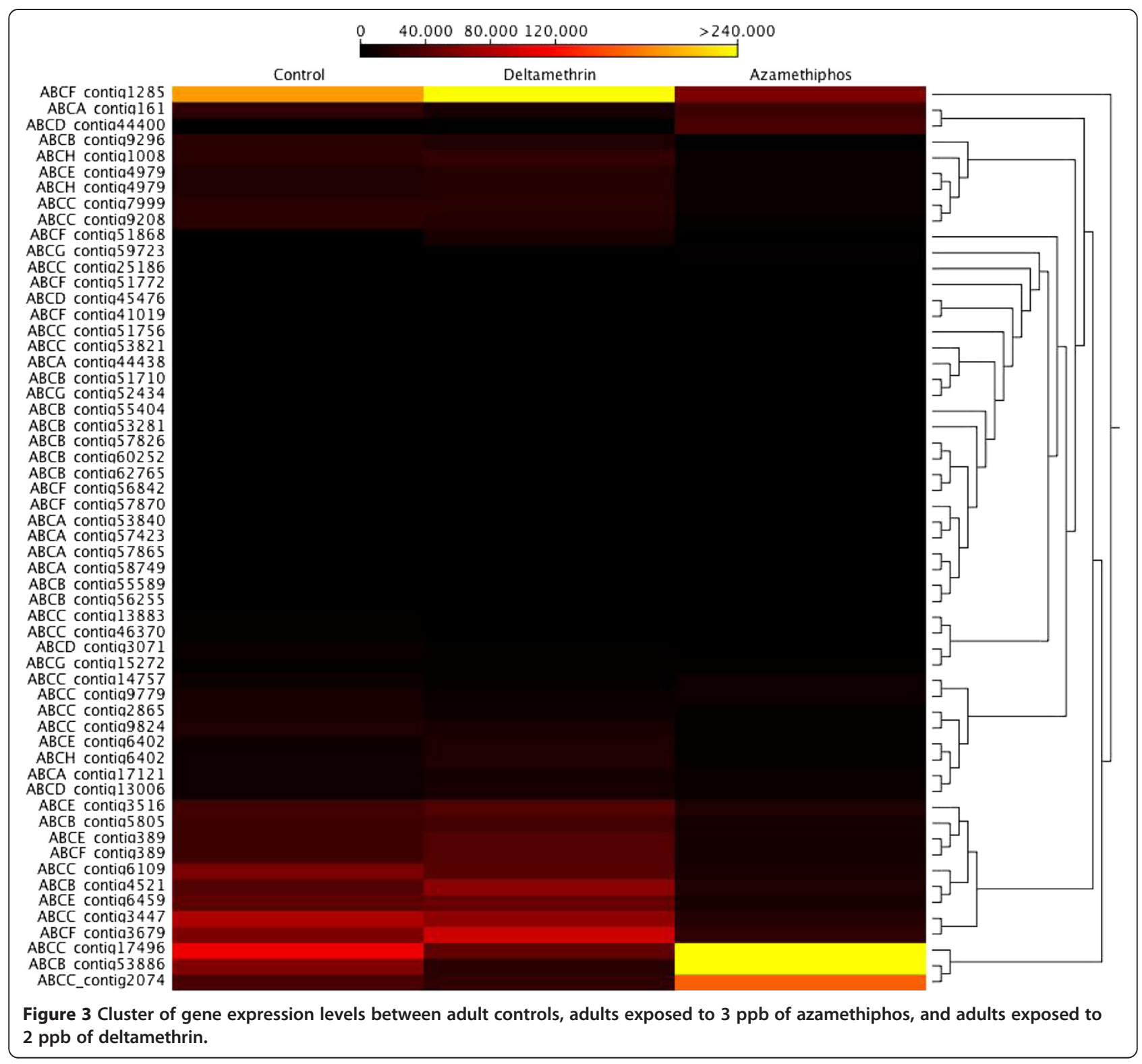

to deltamethrin, the $\mathrm{ABCD} / \mathrm{E} / \mathrm{F}$ subfamilies were highly regulated in adult sea lice (Table 3). Expression profiles of $\mathrm{ABC}$ transporters between females and males were similar (Figure 5). However, the contig 4421 annotated for $\mathrm{ABCB}$ transporter was upregulated in males exposed to deltamethrin, while females presented a high expression of contig 3679 annotated as a member of the ABCF subfamily.Additionally, in order to validate the transcription profiles obtained from sequencing data analysis, RT-qPCR was conducted on one represent of ABC transporters subfamily. The Pearson correlation evidenced a high linear dependence of fold change values obtained from both RNA-Seq and RT-qPCR for each ABC transporters in sea louse exposed to azamethiphos and deltamethrin (Figure 6).
Single nucleotide polymorphism (SNP) mining

A total of 52 SNPs were identified in 17 contigs that annotated for $\mathrm{ABC}$ transporter sequences in C. rogercresseyi (Additional file 1: Table S3). For contigs annotated for the ABCA subfamily, a non-synonymous variation was identified in the TMD2 domain (Additional file 1: Table S3). Three contigs presented SNPs variations for the ABCB subfamily, one of which, contig 9296, had a nonsynonymous variation in the NBD1 domain (Additional file 1: Table S3). For the ABCC subfamily, seven contigs presented SNPs in the open reading frame and 3'UTR regions (Additional file 1: Table S3). In $\mathrm{ABCD} / \mathrm{E} / \mathrm{G} / \mathrm{H}$ subfamilies, the identified variations were synonymous or were present in the 3'UTR region (Additional file 1: Table S3). Nevertheless, more studies are necessary to 
Table 3 Differential transcripts expression for $A B C$ proteins subfamily en adults exposed to delousing drugs and control groups

\begin{tabular}{|c|c|c|c|c|c|}
\hline \multirow[b]{2}{*}{ Feature ID } & \multirow[b]{2}{*}{$A B C$ protein subfamily } & \multicolumn{2}{|c|}{ Deltamethrin vs Control } & \multicolumn{2}{|c|}{ Azamethiphos vs Control } \\
\hline & & Fold change (Log2) & P-value & Fold change (Log2) & P-value \\
\hline contig161 & $A B C A$ & -1.888 & 0 & 1.390 & 0 \\
\hline contig17121 & $A B C A$ & 1.364 & 0 & -1.696 & 0 \\
\hline contig44438 & $\mathrm{ABCA}$ & 0.000 & 0 & 0.000 & 0 \\
\hline contig53840 & $A B C A$ & 1.000 & 1 & 1.000 & 1 \\
\hline contig57423 & $\mathrm{ABCA}$ & 1.000 & 1 & 1.000 & 1 \\
\hline contig57865 & $A B C A$ & 1.000 & 1 & 1.000 & 1 \\
\hline contig58749 & $A B C A$ & 1.000 & 1 & 1.000 & 1 \\
\hline contig4521 & $A B C B$ & 1.637 & 0 & -2.799 & 0 \\
\hline contig51710 & $A B C B$ & 0.000 & 0 & 0.000 & 0 \\
\hline contig53281 & $A B C B$ & 0.000 & $1.83 \mathrm{E}-13$ & 0.000 & $2.36 \mathrm{E}-13$ \\
\hline contig53886 & $A B C B$ & -3.065 & 0 & 3.943 & 0 \\
\hline contig55404 & $A B C B$ & 1.000 & 1 & 0.000 & 0 \\
\hline contig55589 & $A B C B$ & 1.000 & 1 & 1.000 & 1 \\
\hline contig56255 & $A B C B$ & 1.000 & 1 & 1.000 & 1 \\
\hline contig57826 & $A B C B$ & 1.000 & 1 & 1.000 & 1 \\
\hline contig5805 & $A B C B$ & 1.107 & 0 & -3.025 & 0 \\
\hline contig60252 & $A B C B$ & 1.000 & 1 & 1.000 & 1 \\
\hline contig62765 & $A B C B$ & 1.000 & 1 & 1.000 & 1 \\
\hline contig9296 & $A B C B$ & -1.344 & 0 & -11.758 & 0 \\
\hline contig13883 & $A B C C$ & -2.880 & 0 & -8.558 & 0 \\
\hline contig14757 & $A B C C$ & -2.056 & 0 & 1.172 & 0 \\
\hline contig17496 & $\mathrm{ABCC}$ & -2.317 & 0 & 2.817 & 0 \\
\hline contig2074 & $A B C C$ & -1.473 & 0 & 4.793 & 0 \\
\hline contig25186 & $\mathrm{ABCC}$ & -1.553 & 0 & -4.945 & 0 \\
\hline contig2865 & $\mathrm{ABCC}$ & -1.403 & 0 & -5.229 & 0 \\
\hline contig3447 & $A B C C$ & -1.169 & 0 & -4.882 & 0 \\
\hline contig46370 & $A B C C$ & 0.000 & 0 & -2.778 & 0 \\
\hline contig51756 & $A B C C$ & 0.000 & 0 & 0.000 & 0 \\
\hline contig53821 & $\mathrm{ABCC}$ & -1.792 & 0 & 0.000 & 0 \\
\hline contig6109 & $\mathrm{ABCC}$ & -1.346 & 0 & -4.620 & 0 \\
\hline contig7999 & $A B C C$ & 1.043 & 2.45E-05 & -3.440 & 0 \\
\hline contig9208 & $A B C C$ & -1.109 & 0 & -5.464 & 0 \\
\hline contig9779 & $A B C C$ & -2.604 & 0 & -1.776 & 0 \\
\hline contig9824 & $A B C C$ & -1.307 & 0 & -6.285 & 0 \\
\hline contig13006 & $A B C D$ & 1.394 & 0 & -1.665 & 0 \\
\hline contig3071 & $A B C D$ & -1.338 & 0 & -4.260 & 0 \\
\hline contig44400 & $A B C D$ & 3.125 & 0 & 155.119 & 0 \\
\hline contig45476 & $A B C D$ & 0.000 & 0 & 0.000 & 0 \\
\hline contig3516 & $A B C E$ & 1.215 & 0 & -2.187 & 0 \\
\hline contig389 & $A B C E$ & 1.320 & 0 & -3.150 & 0 \\
\hline contig4979 & $A B C E$ & 1.233 & 0 & -2.241 & 0 \\
\hline contig6402 & ABCE & 1.890 & 0 & -2.037 & 0 \\
\hline
\end{tabular}


Table 3 Differential transcripts expression for ABC proteins subfamily en adults exposed to delousing drugs and control groups (Continued)

\begin{tabular}{|c|c|c|c|c|c|}
\hline contig6459 & $\mathrm{ABCE}$ & 1.159 & 0 & -3.435 & 0 \\
\hline contig1285 & $\mathrm{ABCF}$ & 1.226 & 0 & -3.338 & 0 \\
\hline contig3679 & $\mathrm{ABCF}$ & 1.577 & 0 & -2.707 & 0 \\
\hline contig389 & $\mathrm{ABCF}$ & 1.359 & 0 & -3.163 & 0 \\
\hline contig41019 & $\mathrm{ABCF}$ & 0.000 & 0 & 0.000 & 0 \\
\hline contig51772 & $A B C F$ & 0.000 & 0 & 6.135 & 0 \\
\hline contig51868 & $A B C F$ & 8.776 & 0 & -1.255 & $3.85 \mathrm{E}-08$ \\
\hline contig56842 & $\mathrm{ABCF}$ & 1.000 & 1 & 1.000 & 1 \\
\hline contig57870 & $\mathrm{ABCF}$ & 1.000 & 1 & 1.000 & 1 \\
\hline contig15272 & $A B C G$ & 2.250 & 0 & 1.016 & 0.781 \\
\hline contig52434 & $A B C G$ & 0.000 & 0 & 0.000 & 0 \\
\hline contig59723 & $A B C G$ & 0.000 & 0 & 0.000 & 0 \\
\hline contig 1008 & $\mathrm{ABCH}$ & 1.182 & 0 & -3.219 & 0 \\
\hline contig4979 & $\mathrm{ABCH}$ & 1.252 & 0 & -2.339 & 0 \\
\hline contig6402 & $\mathrm{ABCH}$ & 1.715 & 0 & -2.137 & 0 \\
\hline
\end{tabular}

determinate the function of non-synonymous variations in $\mathrm{ABC}$ transporters and the possible association of these with delousing drug resistance.

\section{Discussion}

The ABC family is composed of proteins that include a wide range of compounds both within and exterior to the cell. In eukaryotes, many of the functions that these proteins have in the cell remain unknown. However, in Drosophila melanogaster these proteins have been observed to participate in the modulation of molting hormones such as the ecdysteroids. These transporters have also been found in insects to play a role in insecticide tolerance $[16,40]$. Currently in arthropods, 64, 56, and $46 \mathrm{ABC}$ proteins have been identified in D. pulex [12], Drosophila [16], and T. japonicus [23], respectively. The present study found 57 contigs with homology to the different $\mathrm{ABC}$ proteins subfamilies during distinct larval and adult stages of $C$. rogercresseyi development [35]. Of these contigs, members belonging to eight of the ABC subfamilies $(\mathrm{A}-\mathrm{H})$ described in arthropods were identified [16].

Differences in the expression of the eight $\mathrm{ABC}$ proteins subfamilies were evaluated in silico during the distinct developmental stages of $C$. rogercresseyi. The ABCA subfamily was upregulated during the nauplius III and chalimus III-IV larval stages. The physiological function of this transporter subfamily is still unclear in arthropod organisms [41]. However, in T. castaneium, blocking this subfamily causes mortality in pupae and adults [21]. Taking the results obtained in T. castaneum together with the greater expression levels observed in juvenile $C$. rogercresseyi, it is possible to suggest that the ABCA subfamily plays a role during early ontogenetic development.

In turn, the $\mathrm{ABCB}$ subfamily has been widely studied in humans due to its function as a MRP in studies related to the control of cancer [42,43]. Moreover, this subfamily has been implicated in the molting process and the developmental transition from pupa to adult in T. castaneum [21]. The present study found greater expression levels in juvenile chalimus III-IV stages and in adult $C$. rogercresseyi, which is a result similar to that observed in T. castaneum [21] and T. japonicus [23]. Taken together, these findings indicate greater metabolic activity in response to pharmaceutical treatments during the parasitic stages of $C$. rogercresseyi.

Similar to the ABCB subfamily, ABCC transporters have detoxifying activities and present specific binding sites to drugs (MRPs) [13]. In C. rogercresseyi, transporters associated with $\mathrm{ABCC} 1$ and $\mathrm{ABCC} 4$ were identified and overexpressed throughout the course of the nauplius I-II larval stages. The ABCC1 transporters are considered "long" MRPs and present an extra transmembrane domain in the N-terminal termed $\mathrm{TMD}_{0}$. This is compared to "short" MRPs, among which is ABCC4 [44]. Long MRPs, or MRP1, have been associated with xenobiotic resistance in humans [45], T.ni [28], and $L$. salmonis [31]. Other ABC protein member of this subfamily is the sulfonylurea receptor (SUR). In arthropod SUR proteins have been related to chitin synthesis and in some reports suggest that SUR are putative targets for some insecticide $[16,46]$. For C. rogercresseyi some contigs with high homology with SUR gene were highly 


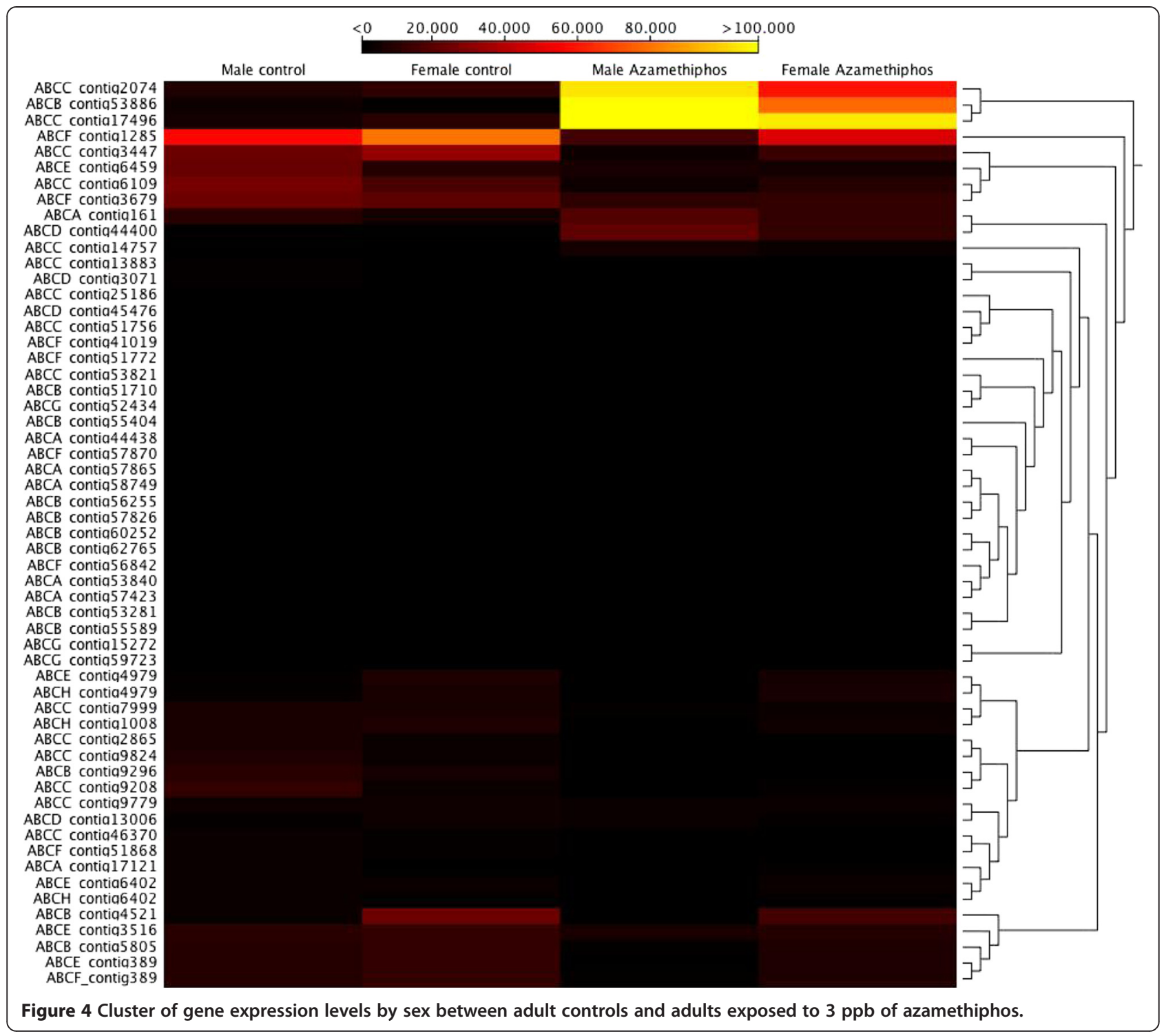

regulated in larval stages, which can be related to the sea lice cuticle biogenesis. On the other hand, the high transcript levels observed during the larval stages of C. rogercresseyi allow for associating the $\mathrm{C}$ subfamily, in addition to its detoxifying characteristics, to processes related to development and maturation during early developmental stages, as has been observed in other invertebrates $[16,47]$.

The ABCD subfamily in C. rogercresseyi was overexpressed in the nauplius I-II and chalimus I-II larval stages. In contrast to other transporter types, this subfamily is found in membrane-bound peroxisome, and its function is to transport fatty acids to the interior of this organelle $[16,41,48]$. These transporters have also been observed to play a role in the metabolism and development of arthropods [49]. Congruent with that observed for $C$. rogercresseyi, this transporter subfamily has been found expressed during all of the developmental stages in T. japonicus [23].

From the infective copepodid stages, an increased expression was observed for the ABCE and ABCF subfamilies in C. rogercresseyi. In humans, the ABCE1 transporter has inhibitory actions on RNase L, an important enzyme related to interferon functions in response to the presence of a virus [48]. It has also been found that blocking the ABCE-F transporters in T. castaneum causes mortality in the pre-pupa stage, thereby impeding development into adults [21]. Moreover, the ABCE transporter presents ubiquitous expression during all developmental stages in T. japonicus [23].

The ABCG subfamily of transporters corresponds to the haft transporter and presents inverted domains in 


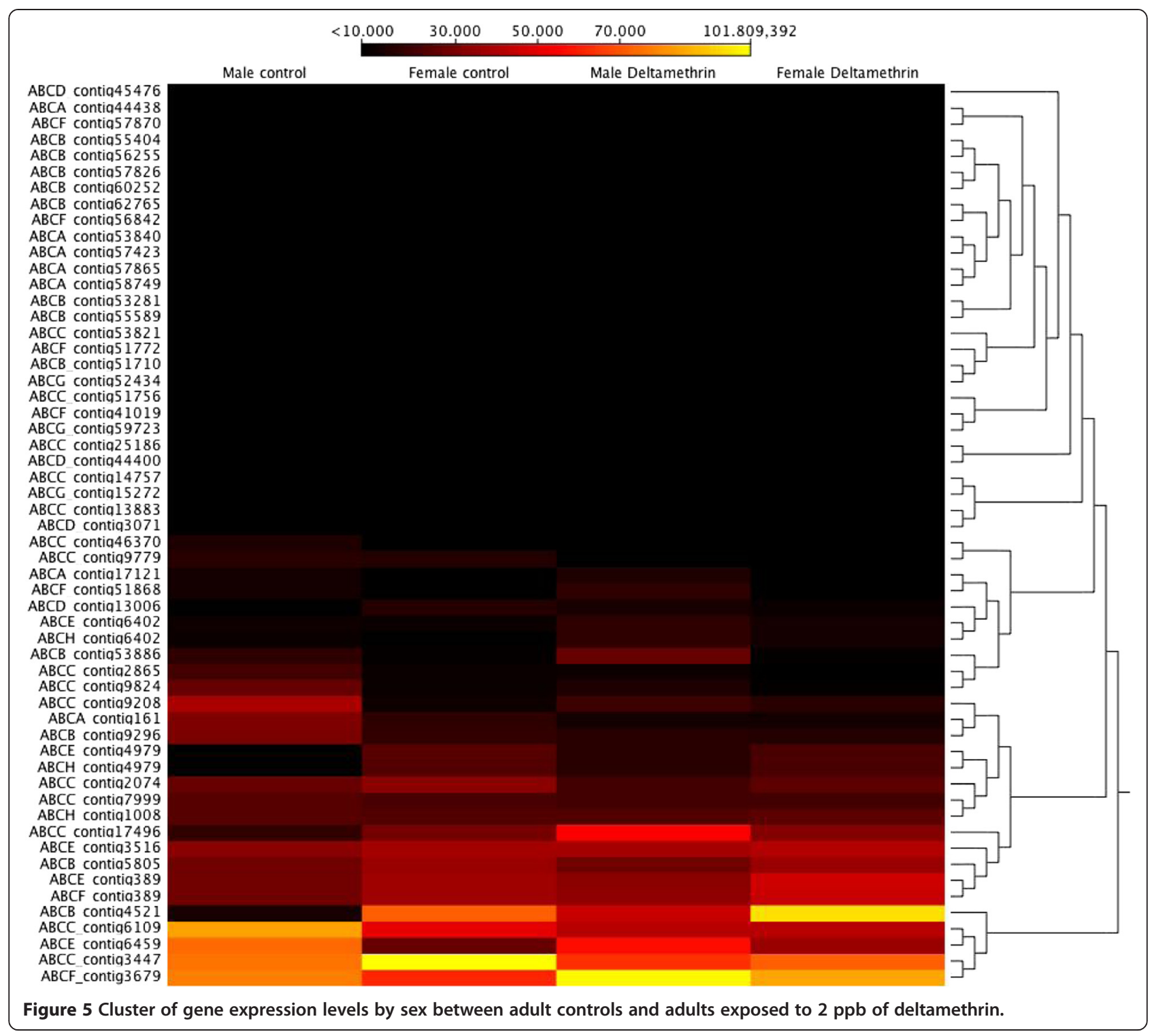

the extreme C-terminal [12]. In $C$. rogercresseyi, this subfamily was principally overexpressed during the nauplius II larval stage. The ABCG transporter is homologous to the white protein that forms heterodimers in D. melanogaster with the brown and scarlet proteins, which themselves act as a precursor to pigmentation [50]. In T. castaneum, the inactivation of this gene provoked an arrest of development during the pre-pupa stages [21]. The ABCG transporters have also been found to induce the expression of genes linked to the molting hormone 20-ecdysone (20E) in D. melanogaster [51]. Given the expression of this transporter during the nauplius II stage in C. rogercresseyi, it could be associated with development towards the copepodid stage.

The final subfamily identified was the $\mathrm{ABCH}$ subfamily, which presents a domain formation similar to that of the
ABCG subfamily [12]. In C. rogercresseyi, three contigs were identified that annotated for the $\mathrm{ABCH}$ subfamily, and these were overregulated in the nauplius II stage. Despite that the function of the $\mathrm{ABCH}$ transporters is still unclear, in T. cantaneum these have been found to play a fundamental role in the transport of lipids to the cuticle, thereby generating a hydrophobic barrier for the organism [21]. On the other hand, in T. urticae these types of transporters could be involved in the process of diapause [52].

The ABC transporters have been widely studied for their role as MRPs, especially the ABCB and ABCC subfamilies. The $A B C$ transporters have been found to participate in the detoxification of pyrethroids and avermectins, among other chemicals generally used in invertebrate pest control [53-55]. For example, increased transcript levels of the 


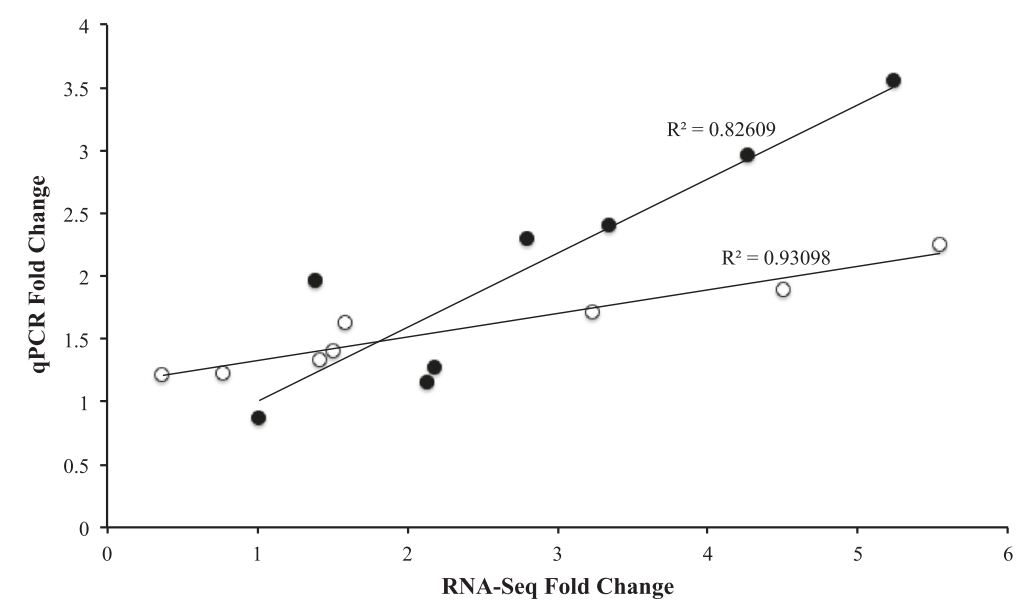

Figure 6 Transcription expression validation for $A B C$ transporters identified from C. rogercresseyi transcriptome in response to delousing drugs. Black circle: linear correlation among $A B C$ transporters selected from RNA-seq and qPCR analysis after 3 ppb of azamethiphos exposure on sea lice. White circle: linear correlation among ABC transporters selected from RNA-seq and qPCR analysis after 2 ppb of azamethiphos exposure on sea lice.

ABCB1 (P-gp) transporter in L. salmonis has been linked to generated resistance to EMB $[10,11]$. Similarly, an increased gene expression of $\mathrm{ABC}$ transporters in $A$. aegypti populations resistant to pyrethroids suggests the participation of these transporters in detoxifying processes [29]. In addition to pyrethroids, the effect of organophosphates on expression levels of $\mathrm{ABC}$ transporters has been evaluated in rats, showing that exposure to diazinon induced an increased intestinal expression of P-gp [56]. Moreover, in resistant strains of Rhipicephalus microplus treated with an inhibitor of $\mathrm{ABCB}$ transporters and exposed to different concentrations of chlorpyrifos, the lethal concentration of this organophosphate was reduced as compared to strains not treated with an inhibitor. These findings reveal the interaction between $\mathrm{ABC}$ transports and the detoxification process of organophosphates [53].

The present study evaluated the transcriptomic response of the $\mathrm{ABC}$ transporters identified in adult $C$. rogercresseyi individuals exposed to the pyrethroid deltamethrin and the organophosphate azamethiphos. For both treatments, the $\mathrm{ABCB}$ and $\mathrm{ABCC}$ transporter subfamilies presented higher expression levels in salmon lice exposed to the pharmaceuticals. Additionally, differences in expression profiles were observed between males and females, a result which has also been obtained in EBM resistant strains of L. salmonis [57]. In regards to the ABCG subfamily, these have been found to transport drugs and sterols [16], and in P. xylostella resistant to insecticides, an increased expression of the $\mathrm{ABCH}$ transporters has been reported, thus suggesting a possible detoxifying role [58]. However, in C. rogercresseyi, no significant change in transcript levels of these two subfamilies was found in adults exposed to deltamethrin or azamethiphos.
The presence of mutations in genes coding for the $\mathrm{ABC}$ transporters can generate changes in molecular functions and related biological processes. For example, mutations in human $\mathrm{ABCD}$ transporters have been found to cause adrenal insufficiency and the demyelination of neurons [59]. Moreover, variations in transporters linked to processes of detoxification can induce resistance in organisms, such as with the insertion of tyrosine in the ABCC4 transporter of Bombyx mori, where strains with this insertion were resistant to the toxin Cry1Ab [60]. Another possible mutation is through SNP variations, which could be an important tool in identifying organisms resistant or susceptible to certain drugs. For example, 13 polymorphisms have been identified in humans in distinct $\mathrm{ABC}$ transporter subfamilies, and these have led to associations between individual responses and distinct therapeutic drug treatments [61]. Apart from this, the nematode Onchocerca volvulus presents alterations in P-gp transporter functions in association with the presence of SNPs that generate non-synonymous changes [62]. The present study identified $17 \mathrm{ABC}$ transporters related to polymorphisms in a single nucleotide. The identified SNPs evidenced both synonymous and nonsynonymous mutations in conserved domains and UTR regions. Future studies will focus on relating the reported mutations with the response of $C$. rogercresseyi to the distinct pharmaceuticals used in infestation control.

\section{Conclusions}

The present study applied genomic approaches to identify 57 sequences annotating for the eight members of the $\mathrm{ABC}$ transporter subfamilies in C. rogercresseyi. The ABC transporters were evaluated in silico and demonstrated changes in expression throughout the developmental 
stages of the salmon louse. Additionally, the expression profiles of $\mathrm{ABC}$ transporters in adult individuals exposed to deltamethrin or azamethiphos were evaluated, finding increased expression levels for the $\mathrm{ABCB}$ and ABCC subfamilies. Finally, mutations were found in 17 $A B C$ transporters, with these being located in both the open reading frame and UTR regions. Future studies will evaluate the effects that the identified SNPs have in C. rogercresseyi strains resistant or susceptible to the drugs used for its control in the Chilean salmon aquaculture industry.

\section{Additional file}

Additional file 1: Table S1. Primer list for $A B C$ transporters identified in C. rogercresseyi for qPCR validation. Table S2. BLASTx analysis of $57 \mathrm{C}$. rogercresseyi ABC proteins. Table S3. List of SNPs identified for ABC proteins from C. rogercresseyi.

\section{Competing interests}

The authors declare that they have no competing interests.

\section{Authors' contributions}

CG-E conceived the idea, performed the experimental analyses collected the samples; W-M performed the sequencing runs; W-M and CG-E performed the bioinformatic analyses; W-M, AS, CG-E led the manuscript's draft preparation. All authors have read and approved the final version of this manuscript.

\section{Acknowledgments}

This study was funded through CONICYT-Chile, FONDAP project grant 15110027. The authors also give thanks to Marine Harvest Chile S.A.

\section{Author details}

${ }^{1}$ Laboratory of Biotechnology and Aquatic Genomics, Interdisciplinary Center for Aquaculture Research (INCAR), University of Concepción, PO. Box 160-C, Concepción, Chile. ${ }^{2}$ Institute of Aquaculture, University of Stirling, Stirling FK9 4LAScotland, UK.

Received: 22 October 2014 Accepted: 15 March 2015

Published online: 09 April 2015

\section{References}

1. Bravo S. Sea lice in Chilean salmon farms. Aquaculture. 2003;23:197-200.

2. Costello MJ. Ecology of sea lice parasitic on farmed and wild fish. Trends Parasitol. 2006;22:475-83.

3. Hamilton-West C, Arriagada G, Yatabe T, Valdés P, Hervé-Claude LP, Urcelay S. Epidemiological description of the sea lice (Caligus rogercresseyi) situation in southern Chile in August 2007. Prev Vet Med. 2011;104:341-5.

4. Oelckers K, Vike S, Duesund H, Gonzalez J, Wadsworth S, Nylund A. Caligus rogercresseyi as a potential vector for transmission of Infectious Salmon Anaemia (ISA) virus in Chile. Aquaculture. 2014;420,Äi421(0):126-32.

5. Torrissen $\mathrm{O}$, Jones $\mathrm{S}$, Asche F, Guttormsen A, Skilbrei OT, Nilsen F, et al. Salmon lice - impact on wild salmonids and salmon aquaculture. J Fish Dis. 2013;36(3):171-94.

6. Cárcamo JG, Aguilar MN, Barrientos C, Carreño CF, Quezada C, Bustos C, et al. Effect of emamectin benzoate on transcriptional expression of cytochromes P450 and the multidrug transporters (Pgp and MRP1) in rainbow trout (Oncorhynchus mykiss) and the sea lice Caligus rogercresseyi. Aquaculture. 2011:321:207-15.

7. Bravo S, Treasurer J, Sepulveda M, Lagos C. Effectiveness of hydrogen peroxide in the control of Caligus rogercresseyi in Chile and implications for sea louse management. Aquaculture. 2010;303:22-7.

8. Grant AN. Medicines for sea lice. Pest Manag Sci. 2002;58(6):521-7.

9. Jones M, Sommerville C, Wootten R. Reduced sensitivity of the salmon louse, Lepeophtheirus salmonis, to the organophosphate dichlorvos. J Fish Dis. 1992;15(2):197-202.
10. Heumann J, Carmichael S, Bron JE, Tildesley A, Sturm A. Molecular cloning and characterisation of a novel P-glycoprotein in the salmon louse Lepeophtheirus salmonis. Comp Biochem Physiol, Part C: Toxicol Pharmacol. 2012;155(2):198-205.

11. Igboeli O, Purcell S, Wotton H, Poley J, Burka J, Fast M. Immunostimulation of Salmo salar L., and its effect on Lepeophtheirus salmonis (Kroyer) P-glycoprotein mRNA expression following subsequent emamectin benzoate exposure. J Fish Dis. 2013;36(3):339-51.

12. Sturm $A$, Cunningham $P$, Dean $M$. The $A B C$ transporter gene family of Daphnia pulex. BMC Genomics. 2009;10(1):170.

13. Dean M, Hamon Y, Chimini G. The human ATP-binding cassette (ABC) transporter superfamily. J Lipid Res. 2001;42(7):1007-17.

14. Higgins CF. ABC transporters: from microorganisms to man. Annu Rev Cell Biol. 1992;8(1):67-113.

15. Hollenstein K, Dawson RJP, Locher KP. Structure and mechanism of ABC transporter proteins. Curr Opin Struct Biol. 2007;17(4):412-8.

16. Dermauw $W$, Van Leeuwen $T$. The ABC gene family in arthropods: Comparative genomics and role in insecticide transport and resistance. Insect Biochem Mol Biol. 2014;45:89-110.

17. Davidson AL, Chen J. ATP-binding cassette transporters in bacteria. Annu Rev Biochem. 2004:73(1):241-68.

18. Roth CW, Holm I, Graille M, Dehoux P, Rzhetsky A, Wincker P, et al. Identification of the Anopheles gambiae ATP-binding cassette transporter superfamily genes. Mol Cells. 2003;15(2):150-8.

19. Liu S, Zhou S, Tian L, Guo E, Luan Y, Zhang J, et al. Genome-wide identification and characterization of ATP-binding cassette transporters in the silkworm, Bombyx mori. BMC Genomics. 2011;12(1):491.

20. Xie X, Cheng T, Wang G, Duan J, Niu W, Xia Q. Genome-wide analysis of the ATP-binding cassette $(A B C)$ transporter gene family in the silkworm, Bombyx mori. Mol Biol Rep. 2012;39(7):7281-91.

21. Broehan $G$, Kroeger $T$, Lorenzen M, Merzendorfer H. Functional analysis of the ATP-binding cassette (ABC) transporter gene family of Tribolium castaneum. BMC Genomics. 2013;14(1):6.

22. Dermauw W, Osborne EJ, Clark RM, Grbić M, Tirry L, Van Leeuwen T. A burst of $A B C$ genes in the genome of the polyphagous spider mite Tetranychus urticae. BMC Genomics. 2013;14(1):317.

23. Jeong C-B, Kim B-M, Lee J-S, Rhee J-S. Genome-wide identification of whole ATP-binding cassette (ABC) transporters in the intertidal copepod Tigriopus japonicus. BMC Genomics. 2014;15(1):651.

24. Szakács G, Annereau J-P, Lababidi S, Shankavaram U, Arciello A, Bussey KJ, et al. Predicting drug sensitivity and resistance: profiling $A B C$ transporter genes in cancer cells. Cancer Cell. 2004;6(2):129-37.

25. Massey P, Fojo T, Bates S. ABC Transporters: Involvement in Multidrug Resistance and Drug Disposition. In: Rudek MA, Chau CH, Figg WD, McLeod HL, editors. Handbook of Anticancer Pharmacokinetics and Pharmacodynamics. New York: Springer; 2014. p. 373-400.

26. Juranka PF, Zastawny RL, Ling V. P-glycoprotein: multidrug-resistance and a superfamily of membrane-associated transport proteins. FASEB J. 1989;3(14):2583-92.

27. Luckenbach T, Epel D. ABCB-and ABCC-type transporters confer multixenobiotic resistance and form an environment-tissue barrier in bivalve gills. Am J Physiol Regul Integr Comp Physiol. 2008;294(6):R1919-29.

28. Simmons J, D'Souza O, Rheault M, Donly C. Multidrug resistance protein gene expression in Trichoplusia ni caterpillars. Insect Mol Biol. 2013;22(1):62-71.

29. Bariami V, Jones CM, Poupardin R, Vontas J, Ranson H. Gene Amplification, ABC Transporters and Cytochrome P450s: Unraveling the Molecular Basis of Pyrethroid Resistance in the Dengue Vector, Aedes aegypti. PLoS Negl Trop Dis. 2012;6(6):e1692.

30. Valenzuela-Muñoz V, Nuñez-Acuña G, Gallardo-Escárate C. Molecular characterization and transcription analysis of P-glycoprotein gene from the salmon louse Caligus rogercresseyi. J Aquaculture Res Dev. 2014;5(236): doi:10.4172/2155-9546.1000236

31. Heumann J, Carmichael SN, Bron JE, Sturm A. Isolation and characterisation of four partial cDNA sequences encoding multidrug resistance-associated proteins (MRPs) in the salmon louse Lepeophtheirus salmonis (Krøyer, 1837). Aquaculture. 2014:424-425:207-14.

32. Bravo $S$, Sevatdal $\mathrm{S}$, Horsberg TE. Sensitivity assessment of Caligus rogercresseyi to emamectin benzoate in Chile. Aquaculture. 2008;282(1,Äi4):7-12.

33. Bravo S, Sepulveda M, Silva MT, Costello MJ. Efficacy of deltamethrin in the control of Caligus rogercresseyi (Boxshall and Bravo) using bath treatment. Aquaculture. 2014;432:175-80. 
34. Helgesen KO, Bravo S, Sevatdal S, Mendoza J, Horsberg TE. Deltamethrin resistance in the sea louse Caligus rogercresseyi (Boxhall and Bravo) in Chile: bioassay results and usage data for antiparasitic agents with references to Norwegian conditions. J Fish Dis. 2014;37(10):877-90.

35. Gallardo-Escárate C, Valenzuela-Muñoz V, Núñez-Acuña G. RNA-Seq analysis using de novo transcriptome assembly as a reference for the salmon louse Caligus rogercresseyi. Plos One. 2014;9(4):e92239.

36. Kal AJ, van Zonneveld AJ, Benes V, van den Berg M, Koerkamp MG, Albermann K, et al. Dynamics of gene expression revealed by comparison of serial analysis of gene expression transcript profiles from yeast grown on two different carbon sources. Mol Biol Cell. 1999;10(6):1859-72.

37. Drummond A. Geneious. v. 5.1 Available from: http://www.geneious.com. 2009.

38. Rozen S, Skaletsky H. Primer3 on the WWW for general users and for biologist programmers. Methods Mol Biol. 2000;132:365-86.

39. Gallardo-Escárate C, Valenzuela-Muñoz V, Nuñez-Acuña G, Chávez-Mardones J, Maldonado-Aguayo W. Transcriptome analysis of the couch potato (CPO) protein reveals an expression pattern associated with early development in the salmon louse Caligus rogercresseyi. Gene. 2014;536(1):1-8.

40. Jones CM, Toé HK, Sanou A, Namountougou M, Hughes A, Diabaté A, et al. Additional selection for insecticide resistance in urban malaria vectors: DDT resistance in Anopheles arabiensis from Bobo-Dioulasso, Burkina Faso. PLoS One. 2012;7(9):e45995.

41. Strauss A, Wang D, Stock M, Gretscher R, Groth M. Tissue-Specific Transcript Profiling for ABC Transporters in the Sequestering Larvae of. 2014.

42. Gillet J-P, Gottesman MM. Mechanisms of multidrug resistance in cancer Springer. 2010;596:47-61.

43. Natarajan $\mathrm{K}$, Xie $\mathrm{Y}$, Baer MR, Ross DD. Role of breast cancer resistance protein (BCRP/ABCG2) in cancer drug resistance. Biochem Pharmacol. 2012;83(8):1084-103.

44. Deeley R, Westlake C, Cole S. Transmembrane transport of endo- and xenobiotics by mammalian ATP-binding cassette multidrug resistance proteins. Physiol Rev. 2006;86:849-99.

45. Cole S, Bhardwaj G, Gerlach J, Mackie J, Grant C, Almquist K, et al. Overexpression of a transporter gene in a multidrug-resistant human lung cancer cell line. Science. 1992;258(5088):1650-4.

46. Abo-Elghar GE, Fujiyoshi P, Matsumura F. Significance of the sulfonylurea receptor (SUR) as the target of diflubenzuron in chitin synthesis inhibition in Drosophila melanogaster and Blattella germanica. Insect Biochem Mol Biol. 2004;34(8):743-52.

47. Roepke TA, Hamdoun AM, Cherr GN. Increase in multidrug transport activity is associated with oocyte maturation in sea stars. Dev Growth Differ. 2006;48(9):559-73.

48. Kashiwayama Y, Seki M, Yasui A, Murasaki Y, Morita M, Yamashita Y, et al. 70-kDa peroxisomal membrane protein related protein (P70R/ABCD4) localizes to endoplasmic reticulum not peroxisomes, and $\mathrm{NH}$-terminal hydrophobic property determines the subcellular localization of $A B C$ subfamily D proteins. Exp Cell Res. 2009;315(2):190-205.

49. Theodoulou FL, Holdsworth M, Baker A. Peroxisomal ABC transporters. FEBS Lett. 2006;580(4):1139-55.

50. Dreesen $T$, Johnson D, Henikoff S. The brown protein of Drosophila melanogaster is similar to the white protein and to components of active transport complexes. Mol Cell Biol. 1988;8(12):5206-15.

51. Liu H, Jia Q, Tettamanti G, Li S. Balancing crosstalk between 20-hydroxyecdysone-induced autophagy and caspase activity in the fat body during Drosophila larval-prepupal transition. Insect Biochem Mol Biol. 2013;43(11):1068-78.

52. Bryon A, Wybouw N, Dermauw W, Tirry L, Van Leeuwen T. Genome wide gene-expression analysis of facultative reproductive diapause in the two-spotted spider mite Tetranychus urticae. BMC Genomics. 2013;14(1):815.

53. Pohl P, Klafke G, Júnior JR, Martins JR, Silva Vaz Jr I, Masuda A. ABC transporters as a multidrug detoxification mechanism in Rhipicephalus (Boophilus) microplus. Parasitol Res. 2012;111(6):2345-51.

54. James CE, Davey MW. Increased expression of $A B C$ transport proteins is associated with ivermectin resistance in the model nematode Caenorhabditis elegans. Int J Parasitol. 2009;39(2):213-20.

55. J-FB P, FB L'H, Liu Z, Prichard RK, Georges E. Reversal of P-glycoprotein-associated multidrug resistance by ivermectin. Biochem Pharmacol. 1997;53(1):17-25.

56. Lecoeur S, Videmann B, Mazallon M. Effect of organophosphate pesticide diazinon on expression and activity of intestinal P-glycoprotein. Toxicol Lett. 2006;161(3):200-9.
57. Igboeli OO, Burka JF, Fast MD. Sea lice population and sex differences in P-glycoprotein expression and emamectin benzoate resistance on salmon farms in the Bay of Fundy, New Brunswick, Canada. Pest Manag Sci. 2014;70:905-14.

58. You M, Yue Z, He W, Yang X, Yang G, Xie M, et al. A heterozygous moth genome provides insights into herbivory and detoxification. Nat Genet. 2013;45(2):220-5.

59. Petriv I, Pilgrim DB, Rachubinski RA, Titorenko VI. RNA interference of peroxisome-related genes in C. elegans: a new model for human peroxisomal disorders. Physiol Genomics. 2002;10(2):79-91.

60. Atsumi S, Miyamoto K, Yamamoto K, Narukawa J, Kawai S, Sezutsu H, et al. Single amino acid mutation in an ATP-binding cassette transporter gene causes resistance to Bt toxin Cry1Ab in the silkworm, Bombyx mori. Proc Natl Acad Sci. 2012;109(25):E1591-8.

61. lida A, Saito S, Sekine A, Mishima C, Kitamura Y, Kondo K, et al. Catalog of 605 single-nucleotide polymorphisms (snps) among 13 genes encoding human atp-binding cassette transporters: abca4, abca7, abca8, abcd1, abcd3, abcd4, abce1, abcf1, abcg1, abcg2, abcg4, abcg5, and abcg8. J Hum Genet. 2002;47(6):285-310.

62. Bourguinat C, Ardelli BF, Pion SDS, Kamgno J, Gardon J, Duke BOL, et al. P-glycoprotein-like protein, a possible genetic marker for ivermectin resistance selection in Onchocerca volvulus. Mol Biochem Parasitol. 2008;158(2):101-11.

\section{Submit your next manuscript to BioMed Central and take full advantage of:}

- Convenient online submission

- Thorough peer review

- No space constraints or color figure charges

- Immediate publication on acceptance

- Inclusion in PubMed, CAS, Scopus and Google Scholar

- Research which is freely available for redistribution 